\title{
Virtual Enterprises and Security
}

\author{
István Mezgár ${ }^{\mathrm{a}}$ and Zoltán Kincses ${ }^{\mathrm{b}}$ \\ ${ }^{a}$ Computer and Automation Research Institute, Hungarian Academy of Sciences, \\ Budapest 1111 Kende u.13-17, Hungary,E-mail: mezgar@sztaki.hu \\ ${ }^{b}$ SEARCH Laboratory, Budapest University of Technology and Economics \\ Budapest 1117 Pázmány Péter st. 1,E-mail: kincses@ludens.elte.hu
}

\begin{abstract}
In the industry the communication security has got an increasing role due to the increasing number of virtual enterprise (VE) realizations. As the basic characteristics of VEs is the communication on the Internet, and during these transactions huge amount of extremely valuable technical data, and information (product, process data besides the business information) are moving between the members of the networks, the security has became a vital problem of this field.

The paper introduces shortly the main characteristics of VEs and some VE reference architectures and the communication architectures and protocols they can use. In the second part the hardware and software security methods, approaches and tools are shortly described that can be applied during the transfer of technical related data, information on the network, and on the computer while storing or handling the information. The main goal of the paper is to call the attention of the industrial community with some examples to the importance of security in (computer) network communication.
\end{abstract}

Keywords: communication security, reference architecture, virtual enterprise

\section{INTRODUCTION}

Secure identification, authentication of the users and communication security are main problems in network communication. In the industry the communication security has got an increasing role since the growing number of virtual enterprise (VE) realizations. The spread of virtual enterprises (VE) and VE-like manufacturing architectures is on the doorstep of the industry. There are many applications, but because of the lack of proper co-operative, effective and secure software tools in the filed the massive spread of real VEs has been pushed into the close future. 
As the basic characteristics of VEs are the communication on the Internet, and during these transactions big quantity of important technical data and information (development-, product-, process data- besides the business information) are exchanged through the networks, so today security is in the focus in these environments.

The paper aims to introduce the existing networked manufacturing architectures, their communication protocols and standards, the connections among the different fields of the networking technology. The description of the connected applications is focusing on the virtual enterprise, on the importance of security in "manufacturing communication", and outlines the possible secure forms of communication for VEs.

The paper doesn't intend to give a full overview, or a detailed description on networking, or on security, rather wants to flesh the dangers of sending valuable information through networks and how to avoid these traps, and push the users in the field of manufacturing into the direction of secure communication.

\section{VE CHARACTERISTICS AND RAs}

\subsection{Characteristics of VE}

There are different forms of the distributed enterprise, but the virtual enterprises are one of the most up-to-date forms of production. Based on the different definitions of VE it can be stated that the intensive use of computer networks and the high-level organization flexibility are main parameters of virtual enterprises. Enterprises forming a holonic manufacturing system are potentially enabled to co-operate with each other to achieve a common goal. This happens in reaction to an external stimulus, taking the form of a new business opportunity which can be better exploited by more joined enterprises than by an individual firm. In these circumstances a virtual enterprise is created [3].

In its current definition, the virtual enterprise is formed by a proper combination of specialized nodes, including financial and engineering firms, manufacturers, assemblers and distributors. This structure can be seen as a holarchy, in that it is a temporary, goal-oriented aggregation of several individual enterprises. Each virtual enterprise is created to pursue a specific business objective, and remains in life for as long as this objective can be pursued. This temporary aggregation is supposed to involve enterprises from different sectors and categories.

After that, the individual nodes resume their independence from each other. Node resources that were previously allocated to the expired business 
are re-directed toward the node individual goals, or toward other virtual enterprises it may have joined.

To allow this kind of dynamic re-configuration of the whole system in response to market changes significant requirements must be met. On one side, individual enterprises must improve their flexibility and extend their connections with the other members of the system. On the other side, the manufacturing infrastructure must support fast interaction as well as information sharing between the nodes. Some of the most significant benefits expected for enterprises joining a virtual organization are:

- New business opportunities become available, by combining the productive capacity and marketing strength of all nodes in the virtual organization.

- Design and development capacity is increased by knowledge sharing between nodes with complementary skills.

- Cost and risk factors for the development of new products are shared among the nodes.

- Due to the specialization of roles within the network, each individual enterprise is enabled to focus on its core processes, thus optimizing and improving them.

\subsection{VE Reference Architectures}

There are different projects to aim some type of general (reference) VE model, or more complete reference architecture. A general model offers limited possibilities but it can have some special characteristic at the same time. The network architecture can be defined as the design principles, physical configuration, functional organization, operational procedures, and data formats used as the bases for the design, construction, modification, and operation of a communications network. Reference architecture is a combination and arrangement of functional groups and reference points that reflect all logically possible network architectures in a structured, flexible, and modular way. Reference architecture gives the general representation of the architecture from which all individual architectures can be derived.

The reasons, or goals to develop reference architectures are to give a complete, and well-defined frame (applying the standards, the ready-to-use of new technologies) for the practical applications. By using the reference architecture the actual individual architectures can be configured easily, and through applied technologies and communication protocols they are platform independent.

The National Industrial Information Infrastructure Protocols (NIIIP) project initialized by the National Institute for Standards and Technology (NIST) is one of the most complete realizations of a VE architectures [5]. It 
intends to bring together the product realization process integration efforts, by developing general global protocols for the technical standards of product data definition, communication, and object technology and workflow management. The NIIIP doesn't intend to develop a new system, rather applying existing standards to consolidate, harmonize, and integrate the many sets of existing protocols. The main goals of the NIIIP reference architecture is to help establishing and operating of VEs in the industry, by applying standardized solutions for VE connectivity, for industrial information modeling and exchange and for Management of VE projects and tasks.

Another architecture has been developed in the PRODNET-II project. The main goal of the PRODNET project was the development of infrastructures to support industrial VEs through the design and development of an open platform and the adequate IT protocols and mechanisms [1]. PRODNET was focused mainly on SMEs in order to support them with tools to inter-operate with other networks. The architecture employs the new emerging standards and advanced technologies in communication, cooperative information management, and distributed decision-making. PRODNET deal with a number of VE environment requirements.

\section{COMMUNICATION REQUIREMENTS AND PROTOCOLS IN VE}

\subsection{Communication requirements in VE}

The basic characteristic of VE is the flexibility both in information- and in material flow. All main events of its life cycle are connected to communication on the network. The communication requirements for a VE can be summarized in the followings:

1. Integration of different communication forms and resources

Communication through connected telephone-, computer- and cable networks, and application possibilities of different protocols, connecting wired- and wireless equipment.

2. Reliable and high quality communication services

Reliability covers the high on-service time (technical reliability), the high availability (well designed/balanced network - resource reliability), the HW and SW security both for equipment and communication lines (access reliability), well controlled/organized networks (organization reliability), all these with reasonable cost.

3. Global time co-ordination

It is essential the exact co-ordination of the different actions in time during the life cycle of the VE, so a general time has to be declared for communication. 
4. Traceable communication

Traceable means to document and audit the communication in a way that fulfils the requirements of bookkeeping (e.g. delivery report and receipt notification) and legal aspects (e.g. digital signature).

As the goal of the present paper is the description of the virtual enterprises from security aspects, in the following the HW and SW security of equipment and communication lines (access reliability) and the control/organization of networks (organization reliability) will be discussed. The security requirements for a VE can be listed as follows:

1. Protection of all types of enterprise data (for all company forming the VE)

2. Privacy and integrity of all types of documents during all phases of storage and communication (Data and communication security - Certification, Encryption),

3. To enable for companies confidential access control,

4. Authorization and authentication of services (digital signature).

These services need to be flexible and customized to meet a wide array of security needs, including specific high-level requirements. In order to fulfill the communication and security demands some basic aspects have to be taken in consideration while selecting security and communication technologies:

1. Platform independent SW tools have to be applied,

2. Standards have to be applied (accepted and "de facto" standards as well),

3. Appropriate architectures with ability to integrate different resources.

Fulfilling all types of the introduced requirements for individual enterprises would be very hard if not possible, so different general network- and organizational structures have been developed, that have been carefully designed and tested. These structures can be defined as reference architectures, and they are available both for the organization and for the information infrastructure of virtual enterprises.

\subsection{Communication Protocols}

There are two basic sets of general communication protocols that are organized in multi-layer architectures.

The Open Systems Interconnection (OSI) - Architecture is a communication system architecture that adheres to the set of ISO standards relating to open systems architecture [4]. The Open Systems Interconnection-Reference 
Model (OSI-RM) is an abstract description of the digital communications between application processes running in differing systems. The model employs a hierarchical structure of seven layers. Each layer performs valueadded service at the request of the neighboring higher layer and, in turn, requests more basic services from the next lower layer. The TCP/IP is two interrelated protocols that are part of the Internet protocol suite. TCP operates on the OSI Transport Layer and breaks data into packets, controls host-tohost transmissions over packet-switched communication networks

In manufacturing communication, there are several protocol architectures that are based on the network reference models and on their protocols. In the followings only a short list is given the most familiar protocols applied in manufacturing environment. The MAP (Manufacturing Automation Protocol), TOP (Technical and Office Protocols), CNMA (Communications Network for Manufacturing Applications), OSACA (Open System Architecture for Controls within Automation Systems), PROFIBUS and Fieldbus are worth to mention protocols. These architectures, or protocols use, or are based on the ISO/OSI reference model, and partly also use its protocols. Recently the techniques and tools supported by OMG are also involved in manufacturing automation.

\section{SECURE COMMUNICATION IN VE}

\subsection{Computer systems and security}

Security can be defined as the state of certainty that computerized data and program files cannot be accessed, obtained, or modified by unauthorized personnel or the computer or its programs. Security is implemented by restricting the physical area around the computer system to authorized personnel, using special software and the security built into the operating procedure of the computer. When applied to computer systems and networks denote the authorized, correct, timely performance of computing tasks. It encompasses the areas of confidentiality, integrity, and availability.

Security is a conscious risk-taking, therefore in every phase of a computer system's life cycle must be applied that security level which costs less than the expense of a successful attack. With other words security must be so strong, that it would not be worth to attack the system, because the investment of an attack would be higher than the expected benefits. At different levels different security solutions have to be applied, and these separate parts have to cover the entire system consistently.

In Table 1 the main practical fields of security are summarized in order to better understand the content of the following sub-chapters. The abbrevia- 
tions of SW and HW have a broader purport in the table not only referring to the computer science.

In the field of security standards and quasi standards have an important role. In the followings some of the most relevant ones are introduced shortly, only to show the directions and status of these significant works.

In order to classify the reliability and security level of computer systems an evaluation system has been developed and the criteria have been summarized in the so-called "Orange book" [6]. Its purpose is to provide technical hardware/firmware/software security criteria and associated technical evaluation methodologies in support of the overall ADP system security policy, evaluation and approval/accreditation responsibilities promulgated by DoD Directive 5200.28 .

Table 1. Main fields of computer security

\begin{tabular}{|c|c|c|c|c|}
\hline & $\begin{array}{c}\text { Organization } \\
\text { security }\end{array}$ & $\begin{array}{l}\text { Personal } \\
\text { security }\end{array}$ & $\begin{array}{c}\text { Network (channel) } \\
\text { security }\end{array}$ & $\begin{array}{c}\text { Computer } \\
\text { (end point) security }\end{array}$ \\
\hline $\begin{array}{l}\text { SW } \\
\text { secu- } \\
\text { rity }\end{array}$ & $\begin{array}{l}\text { Definition of } \\
\text { security pol- } \\
\text { icy (e.g. ac- } \\
\text { cess rights) }\end{array}$ & $\begin{array}{l}\text { Employ- } \\
\text { ment of } \\
\text { trained and } \\
\text { reliable staff }\end{array}$ & $\begin{array}{l}\text { Using tested net- } \\
\text { work SW tools, and } \\
\text { continuously } \\
\text { checked communi- } \\
\text { cation channels and } \\
\text { well configured } \\
\text { network elements }\end{array}$ & $\begin{array}{l}\text { Using tested applica- } \\
\text { tion SW tools, and } \\
\text { continuously checked } \\
\text { operation system, and } \\
\text { properly configured } \\
\text { HW systems }\end{array}$ \\
\hline $\begin{array}{l}\text { HW } \\
\text { secu- } \\
\text { rity }\end{array}$ & $\begin{array}{l}\text { Placing the } \\
\text { computers in } \\
\text { secure loca- } \\
\text { tion of the } \\
\text { building and } \\
\text { offices }\end{array}$ & $\begin{array}{l}\text { Physical } \\
\text { identifica- } \\
\text { tion tech- } \\
\text { nologies } \\
\text { (finger- } \\
\text { prints, etc.) } \\
\end{array}$ & $\begin{array}{l}\text { Prevent direct, or } \\
\text { close access to net- } \\
\text { work cables, or } \\
\text { application of spe- } \\
\text { cial technologies }\end{array}$ & $\begin{array}{l}\text { Prevent direct physi- } \\
\text { cal access to comput- } \\
\text { ers by unauthorized } \\
\text { persons, or a close } \\
\text { access in electromag- } \\
\text { netic way }\end{array}$ \\
\hline
\end{tabular}

The ISO/IEC 10181- [2] multi-part (1-8) "International Standard on Security Frameworks for Open Systems" addresses the application of security services in an "Open Systems" environment, where the term "Open System" is taken to include areas such as database, distributed applications, open distributed processing and OSI. The Security Frameworks are concerned with defining the means of providing protection for systems and objects within systems, and with the interactions between systems. The Security Frameworks are not concerned with the methodology for constructing systems or mechanisms. The Security Frameworks address both data elements and sequences of operations (but not protocol elements) that may be used to obtain specific security services. These security services may apply to the communication entities of systems as well as to data exchanged between systems, and to data managed by systems. 


\subsection{Secure Architectures}

The security architectures represent a structured set of security functions (and the needed hardware and software methods, technologies, tools, etc.) that can serve the security goals of the distributed system. In addition to the security and distributed enterprise functionality, the issue of security is as much (or more) a deployment and user-ergonomics issue as technology issue. That is, the problem is as much trying to find out how to integrate good security into the industrial environment so that it will be used, trusted to provide the protection that it offers, easily administered, and really useful.

The critical security points for virtual enterprises are the access points, the improperly configured systems, the software bugs, the insider threats and the physical security. The following two examples shows how part of these problems are solved in the VE reference architectures.

In NIIIP, secure communication can be implemented at three levels:

- IP level - discussions of protocol-level security are underway within industry organizations.

- OMG level - a Request For Proposal (RFP) for the Security Object Service has been issued.

- NIIIP level - solutions for VE security. NIIIP is proposing an object interface with an extra security tag to activate the enforcement of secure communications over networks. These security requirements can be implemented using well-known data encryption methods available on the Internet. These include Public Key Cryptography from RSA Data Security Inc. and Data Encryption Standard (DES).

The goal of the PRODNET Communication Infrastructure (PCI) is to fulfill the security and the legal requirements besides the functional ones. By using the PCI it is guaranteed that no one, other than the owner, can access to a document (privacy), the content of a document can't be changed without detection (integrity), each received document is unambiguously connected to an identifiable sender (authentication) and the logging information is maintained for auditing and communication management.

\subsection{Security in the Network}

At the beginning of networking there was a need mainly for the reliable operation, but the secure and authentic communication has became a key factor for today. According to Internet users, security and privacy are the most important functions to be ensured and by increasing the security the number of Internet users could be double or triple according to different sur- 
veys. The main reason of the increased demand is the spread of electronic commerce through the Internet, where money transactions are made in a size of millions of dollars a day. It is not just the question of our letters content or our user account, but it is the question of money. False transactions in the real world are not so easy than make them in the insecure virtual world, where the speed and the effect of these false transactions are not only dangerous for the individuals but it is highly dangerous also for big organizations.

Every part of a network could be attacked just the level of expected success and effort determines the targets. From server break-ins (change a Webpage, create false user account, steal information) through DNS spoofing (the attacker falsify the IP address, and the user thinks is surfing a trusted site, but it is not the case, and if the credit card number was given on such a site there is no guarantee that others will not use the card numbers later for their aims) till password or other information stealing every element of network could be dangerous without attention to security.

Experts are arguing with each other and with outsiders too about the strength of each crypto algorithm, but in the first step every algorithm is better than nothing. Instead of FTP there is SFTP (secure FTP) or SCP (secure copy), instead of HTTP there is SHTTP, which is HTTP over SSL (Secure Socket Layer). Instead of simply e-mail there is the PGP (Pretty Good Privacy) signed e-mail. With these techniques it can be guaranteed that the information in e-mail, file or on the Web page will be reached only by authorized parties. These solutions are SHOES (security help-tools over existing solutions), which helps not to walk barefoot on the information superhighway.

In cryptology-based algorithms a key-role has the key-management from issuing state through storage and use till revocation of keys. At issuance it is possible to sign a key by the issuer, and then the issuer must be a wellknown party for others who want to check the signature on this key. If a key is not signed, it is up to us the trustee decision. On each way there is the problem of revoke, because these keys are not forever. Sometimes there are time-stamps on the keys or signatures, sometimes they are used for just one time (for example the One Time Password system), and exists algorithms with merging these two ideas. In this case the One Time Password is a ticket, which has an expiration time.

\subsection{Security of the Computer}

The first line of defense is the physical access of a computer. There is a phrase in security experts' community that every computer is possible to break in, if its console is accessible. Electromagnetic emission is another key 
factor in securing physically a computer from being monitored from distance with specific antennas. Here the tempest room is applied, based on the wellknown Faraday-cage idea.

The password protection is the first step in computer access management. As the next step the private files have to be protected from other users and even from the supervisor, who can access private files on a server even if the owner has not logged in. Therefore in high security systems and today for PC users too there are different CFS solutions (Crypto File System) available, where the content of the hard disk (HD) or home directory is encrypted. After the logon procedure the user has to enter another password than the logon password, which will deactivate the lock algorithm of HD or home directory.

In case of logging into a computer system it is recommended to use an interactive memory-resident virus scanner (under some operating systems, like Windows it is base requirement against viruses) to protect our resources from viruses coming from Internet or intranet or from a colleague's floppy.

The best is when the prevention techniques are applied on different levels. Routers help us in selecting the information by its source of IP address. The firewall filters different services and protocols. The server filters the break-in trials, and user operations from outside and inside too. Local programs are scanning for viruses. There are solutions to filter viruses on the firewall too, but these elements of security services are occasional solutions in specific systems. The required security technologies have to be applied on each level to result the whole system evenly consistent (also called robust).

The training of users has a significant role in that domain. Users will never apply a security technology if there is any less complicated procedure (which is insecure!) than the secure solution. It must be explained for the users, what they can lost without security and what threats they can produce against their user colleagues.

In academic sphere it is not a big problem to trust in system administrators, because there is a non-financial work management. For a bank or for a company it is not allowed to put any other parameter before security, because the profit and the long-term trust is based on the availability and non stop service.

\section{CONCLUSIONS}

Security techniques and technologies have become high priority as different kinds of networking are approaching to each other, sometimes are integrated. This gradual integration is called convergence, and the technology convergence is based on the common application of digital technologies to systems and networks associated with the delivery of services. 
The global nature of communication platforms, particularly the Internet, is providing a key, which opens the door to the further integration of the World economy. The distributed production systems with different sizes will play a definite role, but originating from their openness and flexibility their information systems will be a security risk. They will need complex, flexible security systems that are user friendly and platform independent at the same time. The developments of hardware and software elements of such systems are going on and the potential users have to get acquainted with them. The main goal of this paper was to help this process.

\section{ACKNOWLEDGEMENTS}

Part of the work included in this paper has been done with the support of the OTKA (Hungarian Scientific Research Found) project with the title "The Theoretical Elaboration and Prototype Implementation of a General Reference Architecture for Smart Cards (GRASC)" (Grant No.: T 030 277).

\section{REFERENCES}

[1] Camarinha-Matos, L.M., Afsarmanesh, H., Garita, C., Lima, C., Towards an architecture for virtual enterprises, Keynote paper, Proc. 2nd World, Congress on Intelligent Manufacturing Processes and Systems, Springer, Budapest, Hungary, June 1997, pp. 531-541. - The PRODNET II project, http://www.uninova.pt/ prodnet/

[2] ISO/IEC 10181-1:1996 Information technology -- Open Systems Interconnection -Security frameworks for open systems: Overview.

[3] Mezgár, I. Communication Infrastructures for Virtual Enterprises, position paper at the panel session on "Virtual Enterprising - the way to Global Manufacturing", in the Proc. of the the IFIP World Congress, Telecooperation, 31 Aug.- 4 Sept. Vienna/Austria and Budapest/Hungary, Eds. R. Traunmuller and E. Csuhaj-Varju, pp 432-434.

[4] Tanenbaum, A.S., Computer Networks, Third Edition, Prentice-Hall, 1996.

[5] The NIIIP reference architecture, final document, http://www.niiip.org/publicforum/index-ref-arch.html

[6] Trusted computer system evaluation criteria, Orange book, DoD 5200.28-STD, Department of Defense, December 26, 1985, Revision: 1.1 Date: 95/07/14. 